\title{
Research on the Satisfaction of the Elderly of the Public Transport System
}

\author{
Yuzhao Du ${ }^{*}$, Zhuangzhuang Shao and Wenqi Lu \\ School of Beijing Jiaotong University, Beijing, China. \\ *16120950@bjtu.edu.cn
}

\begin{abstract}
This paper takes the satisfaction of the elderly people on the service quality of public transport system in Xi'an as the research object, and makes an evaluation and analysis. The purpose of this paper is to find out the problems existing in the transit system under the trend of aging population in China, and to put forward suggestions for improvement, and to establish a high-level transit system in line with the travel characteristics of the elderly population. Combining AHP with fuzzy comprehensive evaluation, the index evaluation system is established, and the satisfaction degree of the elderly population is obtained by comprehensive evaluation. It is found that the satisfaction of the elderly in Xi'an to the public transport system is still at a low level, and the improvement direction of the public transport system service in the future is put forward according to the evaluation results of various indicators.
\end{abstract}

Keywords: The elderly; Public transport system service quality; AHP; Fuzzy comprehensive evaluation.

\section{Introduction}

Public transport travel is an important way for residents to travel, and it is also a way advocated by the public transport priority strategy in China.

As a new public transport mode, subway is developing rapidly, but the development of rail transit has the characteristics of long construction cycle and large investment $[1,2]$, so now and for a long time in the future, bus is still the main choice of residents' public travel mode. With the aging trend of urban population becoming increasingly prominent, it is particularly important to improve the care of public transport services for the elderly population [3-5].

\section{Bus System Satisfaction Evaluation Model}

\subsection{Model Evaluation Technical Route}

In order to make the evaluation results more accurate, this study established a suitable evaluation index system.

The analytic hierarchy process and the expert review method are used to determine the weights of the indicators at each level, and the factors of the survey objects are introduced to optimize the method for determining the weight of the analytic hierarchy, so that the weights are more objective.

At the same time, the fuzzy comprehensive evaluation is used to comprehensively evaluate the criteria layer project, and based on this result, a comprehensive evaluation of satisfaction is finally made.

\subsection{Establishment of Indicator System Hierarchy}

In this study, the four indicators of convenience $U_{1}$, comfort $U_{2}$, economy $U_{3}$ and safety $U_{4}$ are used as the criterion level [6], and 15 indicators are selected as evaluation sub-indicators. The subindicators are as follows:

$$
\begin{gathered}
U_{1}=\left\{u_{1}, u_{2}, u_{3}, u_{4}\right\} \\
U_{2}=\left\{u_{5}, u_{6}, u_{7}, u_{8}, u_{9}, u_{10}\right\} \\
U_{3}=\left\{u_{11}, u_{12}\right\} \\
U_{4}=\left\{u_{13}, u_{14}, u_{15}\right\}
\end{gathered}
$$


In the formula: $u_{1}, u_{2}, \ldots, u_{15}$ respectively, walking distance to the station, transfer walking distance, old and weak sick seat tips, in-vehicle reporting system, platform facilities, low-step setting, seat holding, sanitary noise environment, air conditioning ventilation, handrail facility settings, bus fare, waiting time, length of stay, smooth parking, and driver's civilization.

\subsection{Determination of Index Weights at All Levels}

\subsubsection{Criteria Layer Indicator Weight}

The convenience, comfort, economy, and safety of the four indicators of the criterion layer are determined by the analytic hierarchy process with respect to the weight of the satisfaction layer.

The specific calculation steps are as follows:

(1) Construction judgment matrix

In this paper, the judgment matrix established by the nine-scale method is modified by the questionnaire survey results to reduce the subjectivity of the judgment matrix, and the judgment matrix is recorded as the adjustment.

(2) Index weight determination

Consistency check of judgment matrix

Consistency index: $C I=\frac{\lambda_{\max }-n}{n-1}$.

Consistency ratio: $C R=\frac{C I}{R I}$.

In the formula: $\lambda_{\max }$ is the maximum eigenvalue of the judgment matrix; $n$ is the number of indicators; $R I$ is the average consistency index; when $C R<0.10$, it is considered that the consistency of the judgment matrix is acceptable, otherwise the judgment matrix should be corrected appropriately.

Index weight calculation

After the judgment matrix consistency test is passed, the judgment matrix can be used to calculate the index weight. The feature vector $w$ corresponding to the maximum eigenvalue $\lambda_{\max }$ of the judgment matrix $A$ is normalized to obtain the weight of each index.

The feature vector $w=\left(w_{1}, w_{2}, \cdots, w_{n}\right)^{T}$ is normalized, and finally the index weight vector is: $W=\left(W_{1}, W_{2}, \cdots, W_{n}\right)^{T}$.

\subsubsection{Indicator Level Sub-indicator Weight}

The weights of each sub-index in the index layer are determined by the expert evaluation method, and the relevant professionals are organized to evaluate the sub-index weights, and the average weights of all the personnel are taken as the final weight results. Recorded as:

$$
P_{1}=\left\{p_{1}, p_{2}, p_{3}, p_{4}\right\} ; \quad P_{2}=\left\{p_{5}, p_{6}, p_{7}, p_{8}, p_{9}, p_{10}\right\} ; \quad P_{3}=\left\{p_{11}, p_{12}\right\} ; P_{4}=\left\{p_{13}, p_{14}, p_{15}\right\} .
$$

\subsection{Fuzzy Comprehensive Model Evaluation}

In the evaluation and analysis of the index of the criterion layer, the fuzzy comprehensive evaluation [7] is used to calculate the evaluation result of the index.

The calculation steps are as follows:

(1) Let the criterion layer $U_{i}$ be a set of sub-indicators: $U_{i}=\left\{u_{m}\right\}$.

(2) The value vector of index evaluation grade is $E_{i}$, that is: $E=\left(e_{k}\right)$.

(3) The index fuzzy comprehensive evaluation matrix is $R_{i}$, and the single factor $u_{m}$ evaluation vector is $r_{i}=\left(r_{m 1}, r_{m 2}, \cdots r_{m k}\right)$.

(4) Based on the above results, the fuzzy evaluation result is: $S_{i}=P_{i} R_{i}$.

(5) The evaluation value of criterion level items is: $N_{i}=S_{i} E^{T}$. Based on the above calculation results, the comprehensive evaluation value of satisfaction can be obtained. 


\section{Evaluation and Analysis of the Satisfaction Degree of Public Transit System in Xi'an}

\subsection{The Current Situation of Public Transport System and Aging in Xi'an}

In recent years, Xi'an has witnessed rapid development of public transport. In 2014, there were 23 public transport enterprises in Xi'an, with 7769 vehicles, 263 lines, $6106.85 \mathrm{~km}$ in length, 22502 employees, 16.82 benchmarks per 10,000 people, $55.95 \%$ of public transport, 4.8 million passengers per day, and 17.7 million passengers per year. Million [8].

According to the sixth census data, the proportion of the population aged over 60 and over 65 in the total population in Xi'an reached $12.5 \%$ and $8.5 \%$, respectively, and the proportion of the population aged over $10 \%$ and $7 \%$ respectively.

\subsection{Questionnaire Investigation}

In this study, the questionnaire includes four aspects: the survey of the basic characteristics of the elderly, travel characteristics, vehicle environment satisfaction survey, and vehicle environment satisfaction survey.

Questionnaire delivery began in mid-August, 2015, and lasted nearly two weeks. Random sampling and face-to-face questioning were used to investigate the basic coverage of the main urban area of Xi'an. A total of 450 questionnaires were issued, and 449 were actually recovered.

\subsection{Determination of Index Weights at All Levels}

(1) Criteria layer indicator weight

When the survey data is standardized by the nine-scale method, the reference values of convenience, comfort, economy, and security weights are 9, 3.22, 0.35, and 1.17, respectively. Based on this result, the establishment of the judgment matrix is corrected.

The corrected judgment matrix is:

$$
A=\left[\begin{array}{cccc}
1 & 5 & 9 & 7 \\
1 / 5 & 1 & 3 & 1 \\
1 / 9 & 1 / 3 & 1 & 1 / 5 \\
1 / 7 & 1 & 5 & 1
\end{array}\right]
$$

Consistency indicator: $C I=0.0532$; when $n=4, R I=0.90$.

Consistency ratio: $C R=C I / R I=0.0591<0.10$. So the judgment matrix passes the consistency test. The calculated index weight matrix is $W=\left(\begin{array}{llll}0.6719 & 0.1338 & 0.0471 & 0.1472\end{array}\right)^{T}$.

(2) Indicator level sub-indicator weight

The results of the expert review method for the weight evaluation of each sub-indicator are:

$$
\begin{aligned}
& P_{1}=\left(\begin{array}{llll}
0.34 & 0.28 & 0.18 & 0.20
\end{array}\right), \\
& P_{2}=\left(\begin{array}{llllll}
0.16 & 0.16 & 0.24 & 0.14 & 0.11 & 0.19
\end{array}\right) \text {, } \\
& P_{3}=\left(\begin{array}{ll}
0.36 & 0.64
\end{array}\right), \\
& P_{4}=\left(\begin{array}{lll}
0.33 & 0.40 & 0.27
\end{array}\right) \text {. }
\end{aligned}
$$

Comprehensive evaluation of satisfaction

(1) Satisfaction rating level vector

In view of the characteristics of the elderly, the three-level evaluation is used to make the understanding of the elderly people more intuitive and concise. 


$$
E=\left(e_{1}, e_{2}, e_{3}\right)=\{\text { Unsatisfied, common, satisfied }\}
$$

Here is the percentage system evaluation, then the value vector is $E=\left(\begin{array}{lll}30 & 60 & 90\end{array}\right)$.

(2) Membership matrix

Based on the previous three-level evaluation, combined with the statistical information of the questionnaire, the corresponding membership matrix can be obtained:

$$
\begin{aligned}
& R_{1}=\left[\begin{array}{llll}
0.07 & 0.05 & 0.04 & 0.05 \\
0.23 & 0.27 & 0.24 & 0.18 \\
0.70 & 0.68 & 0.72 & 0.77
\end{array}\right]^{T} \\
& R_{2}=\left[\begin{array}{llllll}
0.26 & 0.04 & 0.24 & 0.04 & 0.04 & 0.04 \\
0.71 & 0.36 & 0.36 & 0.23 & 0.32 & 0.36 \\
0.03 & 0.60 & 0.40 & 0.73 & 0.63 & 0.60
\end{array}\right]^{T} \\
& R_{3}=\left[\begin{array}{ll}
0.05 & 0.20 \\
0.81 & 0.67 \\
0.14 & 0.13
\end{array}\right]^{T} \\
& R_{4}=\left[\begin{array}{lll}
0.02 & 0.03 & 0.35 \\
0.10 & 0.27 & 0.17 \\
0.88 & 0.70 & 0.48
\end{array}\right]^{T}
\end{aligned}
$$

(3) Comprehensive evaluation of public transportation system satisfaction

According to the previous calculation, the fuzzy comprehensive evaluation results of each of the four indicators can be obtained as follows:

$$
\begin{aligned}
& S_{1}=\left(\begin{array}{lll}
0.055 & 0.233 & 0.712
\end{array}\right) \\
& S_{2}=\left(\begin{array}{lll}
0.123 & 0.394 & 0.483
\end{array}\right) \\
& S_{3}=\left(\begin{array}{lll}
0.146 & 0.720 & 0.134
\end{array}\right) \\
& S_{4}=\left(\begin{array}{lll}
0.113 & 0.187 & 0.700
\end{array}\right)
\end{aligned}
$$

Combined with the defined evaluation level vector matrix, the specific evaluation scores of the four indicators can be obtained by using the formula $a=b$. After calculating the evaluation scores and weights of the criterion level indicators, the satisfaction evaluation value can be obtained. The detailed results are as follows:

Table 1. Various indicators and comprehensive evaluation.

\begin{tabular}{c|cccc|c}
\hline $\begin{array}{c}\text { Project } \\
\text { Indicator }\end{array}$ & Convenience & Comfort & Economic & Security & Comprehensive Score \\
\hline Score / Weight & $79.71 / 0.6719$ & $70.81 / 0.1388$ & $59.63 / 0.0471$ & $77.61 / 0.1472$ & 77.26 \\
\hline
\end{tabular}

According to the evaluation results, it can be found that the evaluation results of each index are generally good, especially the economic satisfaction evaluation is at a low level. The comprehensive evaluation score of the public transportation system is 77.26. It can be seen that the satisfaction of the public transportation system at this stage is still at a low level. There is a large room for improvement in all aspects. In the future, the improvement of the public transport system should focus on the management of vehicle operation, the improvement of the infrastructure of the public transport system, the comprehensive quality improvement of the public transport system staff, and the welfare policy. Care can build a bus system that is more suitable for the elderly and improve the overall bus system satisfaction. 


\section{Conclusion}

In this paper, analytic hierarchy process (AHP), expert evaluation method and fuzzy comprehensive evaluation model are innovated, and some methods are improved to give full play to their respective advantages, so that the final comprehensive and evaluation results are more reasonable and accurate. The new analytical model is proposed for future analysis of such problems.

Establishing a high-level public transport system which accords with the characteristics of the elderly and improving the satisfaction of the elderly to the public transport system play an important role in the healthy development of the aging society in China. Therefore, the research on the satisfaction degree of the public transport system of the current elderly population can effectively curb the emergence of related social problems by finding problems and improving them in time. This work can be done not only unilaterally by the public transport system, but also by the government, the non-elderly and the elderly.

\section{References}

[1]. Yan Li-yang, Men Xiang-pie. Effect of Rail Transit on Residents' Choice of Traffic Modes [J]. Railway Transport and Economy, 2018, (1):100-105.

[2]. Zhang Feiffer, Liu Beebe, Bi Jun, Chen Jin. Traffic Alternatives for Urban Residents and Affecting Factors A Case Study of Nanjing City [J]. Sichuan Environment. 2012, (3):132-138.

[3]. Chen Ming-wee. Study on satisfactory of urban public transportation system with fuzzy synthesis evaluation method [D]. Chengdu: Southwest Jiao tong University, 2006.

[4]. Liu Wu, LI Wen-zip. Exploration of an index model of passenger satisfaction on urban transit services [J]. Urban Transport of China, 2007, 5(6): 65-69, 13.

[5]. Zhang Qi, Yang Hai. Comprehensive evaluation of the degree of railway passenger satisfaction based on fuzzy factors [J]. Journal of the China Railway Society, 2006, 28(1): 22-25.

[6]. Ebola L, Mazola G. Service quality attributes affecting customer satisfaction for bus transit [J]. Journal of Public Transportation, 2007, 10 (3): 21--34.

[7]. Littman T. Valuing Transit Service Quality Improvements [J]. Journal of Public Transportation, 2008, $11(2): 43$.

[8]. Li Xiao-Hua. The Study of Xi'an Transit Development Planning [J]. Logistics Engineering and Management, 2015, (11): 242-243. 